\title{
Life Prediction of Automotive Vehicle's Door W/H System Using Finite Element Analysis
}

\author{
*Byeong-Sam Kim ${ }^{1}$, KwangSoo Lee ${ }^{2}$ and Kyoungwoo Park ${ }^{3}$
}

\begin{abstract}
A Vehicle's door wireing harness arrangement structure is provided. In vehicle's door wiring harness $(\mathrm{W} / \mathrm{H})$ system is more toward to arrange a passenger compartment than a hinge and a weatherstrip. This article gives some insight into the dimensioning process, with special focus on large deflection analysis of wiring harness $(\mathrm{W} / \mathrm{H})$ in vehicle's door structures for durability problem. A Finite elements analysis for door wiring harness $(\mathrm{W} / \mathrm{H})$ is used for residual stresses and dimensional stability with bending flexible. Durability test data for slim test specimens were compared with the numerical predicted fatigue life for verification. The final lifing of the component combines the effects of these microstructural features with the complex stress state arising from the combined service loading and residual stresses.
\end{abstract}

\section{INTRODUCTION}

In vehicle's door wiring harness $(\mathrm{W} / \mathrm{H})$ system is more toward to arrange a passenger compartment than a hinge and a weatherstrip. An opening/closing member of a vehicle is attached to a vehicle by a hinge in a manner enabling easy opening and closing of the opening/closing member. Such members include doors, such as side-doors and rear doors, and other opening/closing members, such as trunk lids. Definitely any wiring harness, it should have sufficient strength to withstand any abrupt situations without affecting the performance of the total system. Fig.1 shows the typical wiring harness system of the front portion of the car [1], [2]. An automotive electronic system has been able to anticipate their needs for reliable and cost effective connection systems. A vehicle's wiring harness $(\mathrm{W} / \mathrm{H})$ system keeps everything else going, powering every component, every switch, and every

\footnotetext{
${ }^{1}$ Department of Automotive, Hoseo University, Asan, visiting professor of Pole Universitaire Leonard de Vinci, France, E-mail: kbs@hoseo.edu

${ }^{2}$ Department of Automotive, Hoseo University, Asan, Korea

${ }^{3}$ Department of Mechanical, Hoseo University, Asan, Korea

* To whom correspondence should be addressed
} 
device. It's the vehicle's central nervous system. It must work, every time and all the time.

Without connection system, no system will work; it will play vital role any industry whether in automotive. The main function of the connection system is to distribute the power supply from one system to another system.
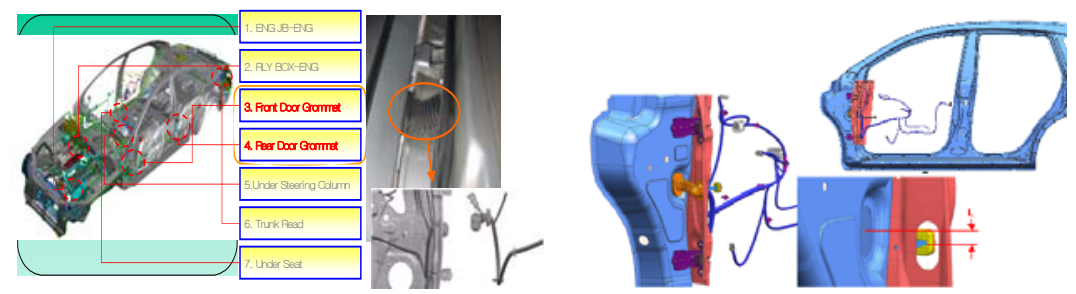

Fig. 1. Automotive front door wiring harness (W/H) system: open/close position

The wiring harness system must not only conform to such mechanical performance requirements; like strength, engage force, mating force, durability, but also to electrical performance requirements like low level termination resistance, voltage drop, isolation resistance, temperature rise. In arranging a wire harness on a vehicle door, when the wire harness is arranged from a passenger compartment side of an inner panel to the body side of the door, the wire harness is not passed through an aperture so that installment becomes easy. However, since the wire harness is arranged at a point closer to the passenger compartment side than a hinge joining the body and the door, it becomes necessary to extend or contract the wire harness as the door is opened or closed.

However, when following the above-noted opening/closing operation, W/H system was a problem of the fatigue, where a tube, grommet, copper etc after 1 or $5 \times 10^{5}$ cycle. This paper gives some insight into the dimensioning process, with special focus on fatigue analysis of W/H in vehicle's door structures [3].

\section{Finite Element Analysis}

\subsection{Definition of Model}

The large deflection problem considered in this study is to behaviour of front door due to the physical JIG design for test results performance, reliability data for analysis. Fig. 1 shows extracted from the body and door structure of the wire line as a reference guide to using sweep capabilities to create a solid model. The scope of this work into develops a slam tester method. The slam tester is designed by Packard Korea in collaboration with GM-Daewoo. An endurance life prediction of 
door $\mathrm{W} / \mathrm{H}$ is used finite element analyses and slim tester with Fig. 1. In automotive industry a long development period is necessary to secure the safety and the reliability of the vehicle within the fatigue and durability considerations.

The slam test is necessary to extend these investigations to the $\mathrm{W} / \mathrm{H}$ while the door is opened and closed. The cause of W/H failure is analyzed by the slam tester [4]. Each time the door is opened or closed the $\mathrm{W} / \mathrm{H}$ is subjected to combined tension/bending loading. Hence a nonlinear large deflection analysis needs to be performed to find out the resulting plastic deformation after the towing loads are removed.

\subsection{FEM Modeling for $\mathbf{W} / \mathrm{H}$}

Each of the finite element models created for the different test configurations in this work were developed with a computer aided design pre-processor. The W/H front door finite element models had the same cable bundle configuration as the samples used in the experimental tests. Some geometrical assumptions were used to represent the $\mathrm{W} / \mathrm{H}$ and to simplify the 3D model. We estimate that the stiffeners of the outside tape are negligible. Table 1 shows the 3D model of the bundle composed of 19 wires of $0.19 \mathrm{~mm}$ diameter.

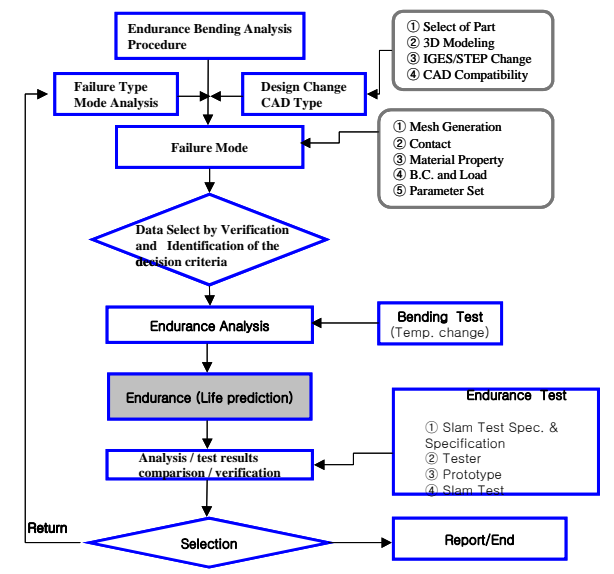

Fig. 2. Diagram for analysis procedure

\subsection{FEM Dynamic Analysis}

The analyses were performed using the commercial nonlinear finite element code ABAQUS Explicit v6.6 [5], [6] executed on IBM an IBM A-Pro(dual CPU $2 \mathrm{GHz}$ ). The Abaqus explicit dynamics procedure performs a large number of 
small time increments efficiently. An explicit central-difference time integration rule is used; each increment is relatively inexpensive (compared to the directintegration dynamic analysis procedure available in Abaqus/Standard) because there is no solution for a set of simultaneous equations. The explicit dynamics analysis procedure is based upon the implementation of an explicit integration rule together with the use of diagonal ("lumped”) element mass matrices[7]-[10].

The equations of motion for the body are integrated using the explicit centraldifference integration rule [6].

$$
\begin{aligned}
& \dot{u}_{(i+1 / 2)}^{N}=\dot{u}_{(i-1 / 2)}^{N}+\frac{\Delta t_{(i+1)}+\Delta t_{(i)}}{2} \ddot{u}_{(i)}^{N} \\
& u_{(i+1)}^{N}=u_{(i)}^{N}+\Delta t_{(i+1)} \dot{u}_{(i+1 / 2)}^{N}
\end{aligned}
$$

where $\mathrm{u}^{\mathrm{N}}$ is a degree of freedom and the subscript $i$ refers to the increment number in an explicit dynamics step. The central-difference integration operator is explicit in the sense that the kinematic state is advanced using known values of $\dot{u}_{(i-1 / 2)}^{N}$ and $\ddot{u}_{(i)}^{N}$ from the previous increment. The explicit integration rule is quite simple but by itself does not provide the computational efficiency associated with the explicit dynamics procedure. The key to the computational efficiency of the explicit procedure is the use of diagonal element mass matrices because the accelerations at the beginning of the increment are computed by

$$
\ddot{u}_{(i)}^{N}=\left(M^{N J}\right)^{-1}+\left(P_{(i)}^{J}-I_{(i)}^{J}\right)
$$

where $M^{N J}$ is the mass matrix, $P^{N J}$ is the applied load vector, and $I^{N J}$ is the internal force vector. A lumped mass matrix is used because its inverse is simple to compute and because the vector multiplication of the mass inverse by the inertial force requires only $n$ operations, where $n$ is the number of degrees of freedom in the model. The explicit procedure requires no iterations and no tangent stiffness matrix.

\subsection{Material Properties}

The tube material is supposed to be the same as the wires one. The wire material is copper alloy their properties are given by Packard Korea [3], [4]. The characteristics of the $\mathrm{W} / \mathrm{H}$ are presented in Table 1 . Several factors are very important in the test, but this study, is difficult to proceed as it did not fit the exclusion, and environmental, tolerance criteria of the cable as shown in Table 1. The material properties are used for the $\mathrm{W} / \mathrm{H}$ is Elasto-Plastic materials 
Table 1. Specification of W/H type by Standard AVSS series (unit:mm)

\begin{tabular}{ccccccc}
\hline \hline Section & $\begin{array}{c}\text { Cable } \\
\text { bundle } \\
\text { /diameter }\end{array}$ & $\begin{array}{c}\text { Wire Di- } \\
\text { ameter }\end{array}$ & $\begin{array}{c}\text { Thickness } \\
\text { of Cable }\end{array}$ & \multicolumn{2}{c}{ Outside Diameter } & Resis- \\
Standard & Max & \\
\hline 0.3 & $7 / 0.26$ & 0.8 & 0.3 & 1.4 & 1.6 & 50.2 \\
0.5 & $7 / 0.32$ & 1.0 & 0.3 & 1.6 & 1.7 & 32.7 \\
0.85 & $19 / 0.24$ & 1.2 & 0.3 & 1.8 & 1.9 & 21.7 \\
1.25 & $19 / 0.29$ & 1.5 & 0.3 & 2.1 & 2.2 & 14.9 \\
20. & $37 / 0.26$ & 1.8 & 0.4 & 2.6 & 2.7 & 9.5 \\
\hline \hline
\end{tabular}

\subsection{Boundary Condition}

The contacts interactions are considered between the cables. To avoid the out of plane deformation of the 19 wires, they are enveloped by a tube represented by a shell $0.15 \mathrm{~mm}$ thickness. A rotation is imposed to the bundle, and represents the opening of the door by $75^{\circ}$. This rotation induced two bending/torsion moments of the wires. In Table 1 we easily identify the damage of the wire. For the 7 cable bundle cable, with a depth of $50 \mathrm{~mm}$ and wires length of $600 \mathrm{~mm}$, the resistance value changes of the 350,000 cycles.

\section{Slam Test}

\subsection{W/H Test Model}

The slam test is necessary to extend these investigations to the $\mathrm{W} / \mathrm{H}$ while the door is opened and closed. The cause of $\mathrm{W} / \mathrm{H}$ failure is analyzed by the slam tester [11]. Each time the door is opened or closed the $\mathrm{W} / \mathrm{H}$ is subjected to combined tension/bending loading. The results of SEM analysis by Standard AVSS 0.5SQ sample 14 discovered optical form shown in the Table 1 . The W/H failure by the crack is estimated to occur in the passed-up elastic tube, and in the inner copper cable. This failure can be considered in this kind of problem: number of bundle in a wire, cable diameter, clearance, elasticity of the tube, etc. The slam tester design cause failure analysis to be presented through the design guide line [1], [2] and [12], but all car manufacturers, has their own unique features and systems design expertise. 


\subsection{Test Setting}

The test equipment is configured such as the door opened/closed 10 times/min, the resistance of the each wire is measured every 10,000 cycle beyond the 50,000 cycle to 350,000 cycles [13]-[15]. Actual vehicle front door W/H mainly applies a 7 cable bundles and 19 cable bundles. In Table 2 we easily identify the damage of the wire.

\section{Results and Discusion}

The history of cycle loading can be considered as a sine curve and correspondents to opening/closing of the door by $75^{\circ}$. The Fig. 3 presents the damage criteria over the wires. A value of 1 of these criteria indicates that a crack has occurred. The life cycle obtained by the experiments $(300,000)$ is 3 times higher than the 100,000 cycle's service life usually used. This is means that larger number of cable with wire is not less than the variation mode is a lot more flexible and also stresses that the work can be seen. In addition, if the same contribute with cable larger depth with door body stresses that the work can be found in Table 2. The numerical and experimental results obtained for 7 wires and 19 wires bundles are presented and compared in Table 3, for the $50 \mathrm{~mm}$ depth case. The numerical result seems to be approved by the experimental tests. Through comparison of the above, the method of endurance analysis and results of wire harness for the endurance of flexible bending can secure the trust were shown in Table 2.

Table 2. Results of maximum stresses and endurance life cycles for the different cases (unit $\mathrm{N} / \mathrm{mm}^{2}$ )

\begin{tabular}{lllll}
\hline \hline Cable No & Case 1 & Non linear & Max. Stress & 7.26 \\
/Diameter & (Depth 50mm) & Endurance & Cycle & 487,000 \\
$(7 / 0.32 \mathrm{~mm})$ & Case 2 & Non linear & Max. Stress & 6.87 \\
& (Depth 100mm) & Endurance & Cycle & 518,000 \\
& Case 3 & Non linear & Max. Stress & 3.04 \\
& (Depth 150mm) & Endurance & Cycle & 600,000 \\
\hline Cable No & Case 4 & Non linear & Max. Stress & 3.78 \\
$/$ Diameter & (Depth 50mm) & Endurance & Cycle & Infinite \\
$(19 / 0.19 \mathrm{~mm})$ & Case 5 & Non linear & Max. Stress & 3.62 \\
& (Depth 100mm) & Endurance & Cycle & Infinite \\
& Case 6 & Non linear & Max. Stress & 1.60 \\
& (Depth 150mm) & Endurance & Cycle & Infinite \\
\hline \hline
\end{tabular}


If the number of cable with the same time as a big difference depth knows that the endurance life cycle is improved [8]. The results obtained for the 6 cases of the Table 2 and Table 3 shows that:

- the 19 wires bundle is more flexible than the 7 wires bundle.

- the maximum stress level is higher in the 7 wires bundle.

- $\quad$ the stress level is higher for the $50 \mathrm{~mm}$ depth cases in Table 3.

Table 3. Compare with slam test results and endurance analysis

\begin{tabular}{ccccc}
\hline Evaluation & $\begin{array}{c}\text { No of cable } \\
\text { /Diameter }\end{array}$ & Standard & $\begin{array}{c}\text { FE Analysis } \\
\text { Result }\end{array}$ & Test Result \\
\hline $\begin{array}{c}\text { Endurance Life Cycle } \\
\text { (Depth 50mm) }\end{array}$ & $7 / 0.32 \mathrm{~mm}$ & 100,000 & 487,000 & 353,054 \\
\hline \hline
\end{tabular}
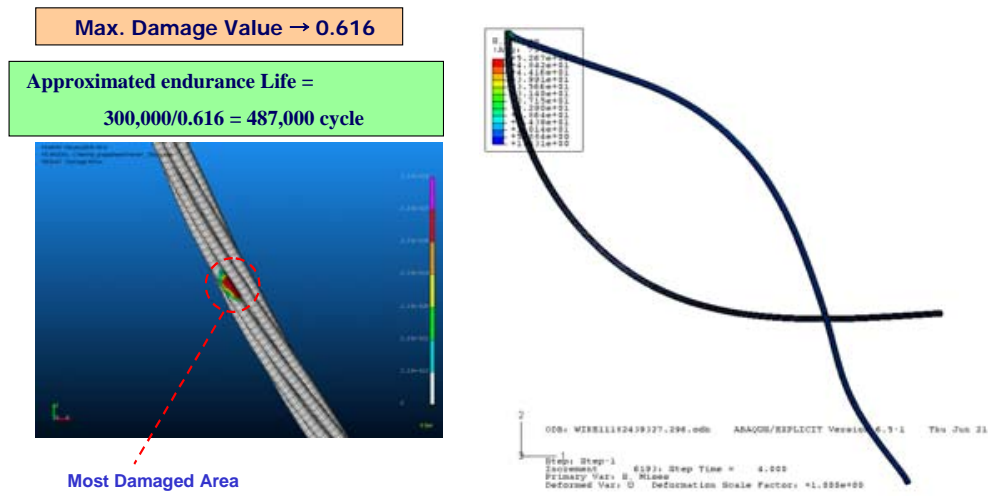

(a) Endurance analysis for case 2 (b) Maximum deflection of cable bundle

Fig. 3. Damage criteria and endurance life cycle

\section{CONCLUSION}

From the FE analysis results, it indicates that the results are well within the design standards. By adopting FE analysis using ABAQUS and FEMFAT, it not only saves time, money \& slam testing but also guides the product engineer for further improvement and modification of the $\mathrm{W} / \mathrm{H}$ system. The biggest challenges of such analyses are: FE modeling of the wiring hardness with analytical rigid sur- 
faces and dealing with convergence issues due to large deformation of the elements. This research to improve the endurance life of $\mathrm{W} / \mathrm{H}$ required for the life cycle design, analysis and testing for the integration of these technologies and secure source technology to derive prototype has been applied, the following were able to obtain useful results. The slam tester, designed and built by the vehicle's test was able to reduce the time and cost. The endurance life cycle how to establish durable, and is designed to help improve productivity, and to be tested. Through comparison of the test results and analysis, vehicle's W/H of the results for the endurance can secure the trust wires, depth due to the number of design guidelines to provide for the endurance life efficiency.

\section{References}

[1] Bungo E.M., Rausch C. (1990) Design Requirements for: Metric-Pack and Global Termina. Packard Electric internal report, Warren, Ohio.

[2] Packard Electric (1984) Environmentally protected connector systems. Packard Electric internal report, Warren, Ohio.

[3] Kim B.S., Lee K. S. (2007) Life prediction analysis of wiring harness system for automotive vehicle. Internal report of Hoseo University.

[4] Lakshmi B., N. William G., Bhatia S. A (2006) Non-linear finite element analysis of typical wiring harness connector and terminal assembly using ABAQUS/CAE and ABAQUS/Standard. 2006 ABAQUS users' conference, Vol. 1: 345-357.

[5] ABAQUS User's Manual Ver. 6.6 (2007) Dausault Systems Inc.

[6] ABAQUS Example Problems Manual (2007) Volume I, 6.2(ed).

[7] Miller K., Joldes G., Lance D., and Wittek A (2007) Total Lagrangian explicit dynamics finite element algorithm for computing soft tissue deformation, Communications in numerical methods in eng., Vol. 23, No. 2:121-134.

[8] G. Lingtian, L. Kaishin, and L. Ying (2007) A meshless method for stress-wave propagation in anisotropic and cracked media”, International Journal of Engineering Science, Vol. 45, Issues 2-8: 601-616.

[9] Benjamin G., Andrew I. and Peter K. (2008) Sensitivity Analysis of Real-Time Systems. Int. J. of Computer Science, Vol. 3 No. 1:6-13.

[10] Park K., Kim B. S., Lim H.J., and all (2007) Performance improvement in internally finned tube by shape optimization. Int. J. of Applied Science, Eng. and Technology, Vol. 4 No. 3.

[11] Fermer M., Svensson H. (2001) Industrial experiences of FE-based fatigue life predictions of welded automotive structures. Fatigue \& Fracture of Eng. Materials and Structures, Vol. 24, No. 7: 489-500.

[12] Aichberger W., Riener H., and Dannbauer H.(2007) Regarding influences of production processes on material parameters in Fatigue Life Prediction. SAE 2007 World Congress, Vol.26, Detroit.

[13] Gaier C., Kose K., Hebisch H., Pramhas G. (2005) Coupling forming simulation and fatigue life prediction of vehicle components. NAFEMS 2005 Int. conference, Malta.

[14] Halászi C., Gaier C., Dannbauer H. (2007) Fatigue life prediction of thermo-machanically loaded engine components. 11th European automotive congress, Budapest.

[15] FEMFAT User's Manual Ver. 4.6 (2007) MAGNA Prowetrain Inc.. 